\title{
The influence on gene-expression profiling of osteoblasts behavior following treatment with the ionic products of sintered $\beta$-dicalcium pyrophosphate dissolution
}

\author{
Jui-Sheng Sun ${ }^{\mathrm{a}, \mathrm{b}}$, Walter Hong-Shong Chang ${ }^{\mathrm{c}}$, Li-Ting Chen ${ }^{\mathrm{a}, \mathrm{c}}$, Yi-Chau Huang ${ }^{\mathrm{d}}$, \\ Lee-Wei Juang ${ }^{\mathrm{d}}$, Feng-Huei Lin ${ }^{\mathrm{a}, \mathrm{d}, *}$ \\ ${ }^{a}$ Department of Biomedical Engineering, National Taiwan University Hospital, Taipei, Taiwan, ROC \\ ${ }^{\mathrm{b}}$ Department of Orthopedic Surgery, National Taiwan University Hospital, Taipei, Taiwan, ROC \\ ${ }^{\mathrm{c}}$ Department of Biomedical Engineering, Chung-Yuan Christian University, Zhong-Li, Tao-Yuan, Taiwan, ROC \\ ${ }^{\mathrm{d}}$ Institute of Biomedical Engineering, National Taiwan University, No. 1, Jen-Ai Road, Taipei, Taiwan, ROC
}

Received 14 October 2002; accepted 1 July 2003

\begin{abstract}
Sintered dicalcium pyrophosphate (SDCP) is biocompatible to bone tissue both in the in vivo and in vitro model. However, the molecular mechanisms that mediated these processes have yet to be identified. In this study, we investigated the influence of SDCP ions on in vitro osteoblasts behavior. The powder of sintered $\beta$-dicalcium pyrophosphate (SDCP) was dissolved by $\mathrm{HCl}$ and then diluted into different concentration of solutions by culture medium used in the osteoblast cell culture. The effects of various concentration of SDCP on bone cell activities were evaluated by using MTT assay. For the differentiation of osteoblasts, alkaline phosphatase (AP) staining, von Kossa stain for mineralized nodules and bone markers messenger ribonucleic acid (mRNA) isolation and identification were performed at $3 \mathrm{~h}$, days $1,3,7$ and 14 .

In the presence of $10^{-8} \mathrm{M}$ SDCP for 14 days, the osteoblasts population was still significantly higher than that of control. In the qualitative analysis for the formation of AP staining colonies and mineralization nodules formation were not affected by SDCP ions. When osteoblasts cultured in the presence of $10^{-8} \mathrm{M}$ SDCP ions, the osteocalcin mRNA expression was up-regulated; while the collagen, osteonectin and osteopontin mRNA expression were down-regulated.

In this study, we demonstrated that the elevated concentration of calcium and pyrophosphate ions can activate genes of the bone cells. This study will contribute to a better understanding of cell/biomaterial interactions and mechanisms that SDCP affect the bone cells.
\end{abstract}

(C) 2003 Elsevier Ltd. All rights reserved.

Keywords: Gene expression; Sintered dicalcium pyrophosphate; Biocompatability; Osteoblastic cells

\section{Introduction}

Recent advancement in orthopedic surgery can be attributed to the revolution in biomaterials. Initially, the choice of biomedical materials for use in the body was dependent on those already available off the shelf. Later, many of the materials selected proved to be either pathogenic or toxic. Whereas second-generation biomaterials were designed to be either resorbable or bioactive, the next generation of biomaterials is combining these

*Corresponding author. Institute of Biomedical engineering, National Taiwan University, No. 1, Jen-Ai Road, Taipei, Taiwan, ROC. Tel.: 886-22-312-3456x1449; fax: 886-22-391-2641.

E-mail address: double@ha.mc.ntu.edu.tw (F.-H. Lin). two properties. Third-generation bioactive glasses and macroporous foams are being designed to activate genes that stimulate regeneration of living tissues [1].

Sintered dicalcium pyrophosphate (SDCP) appear to be biocompatible to bone tissue in the in vivo animal model [2]. Host tissue responses to this material are generally assessed by morphological and histological examinations of the implant site in order to evaluate their biocompatibility with respect to cytotoxicity. It is difficult to exam in vivo reaction of a specific cell to the substrate because numerous cell populations and chemical factors are involved in implantation. In order to determine the sequences of events and the parameters influencing the interactive process, in vitro studies on bone cell culture models are used to determine 
biocompatibility and to investigate bone and biomaterial interactions. Osteoblastic cells (responsible for bone formation) are used most frequently [3-7] and osteoclasts (cell responsible for bone resorption) are also used but less frequently $[8,9]$.

In the in vitro model, SDCP has been proved to be more biocompatible than hydroxyapatite [10]. Recent work in our institute has also demonstrated that the ingestion of either bisphosphonate [11] or SDCP decreased the bony porosity and increased bone mineral contents in the long bones of ovariectomized rats [12]. In the later study, we demonstrated that SDCP can induce apoptosis of osteoclasts in an ultrastructural model characterized by changes of the nucleus accompanied by degradation of cellular organelles [13]. However, the molecular mechanisms that mediated these processes have yet to be identified. Furthermore, it has not been possible to define whether stimulation of bone synthesis by SDCP occurs through direct contact between substrate and cells or through soluble ions released by SDCP during its resorption.

Collagen Type I is synthesized from procollagens that are secreted in the extracellular space. Type I collagen is the most abundant collagen in vertebrates, forms $90 \%$ of the organic mass of bone, and is produced in large quantities by osteoblasts [14]. Osteocalcin is one of the most abundant non-collagenous proteins in bone, but the biologic function of osteocalcin has not been precisely defined. Because of the specific interaction with hydroxyapatite, osteocalcin has been postulated to affect the growth or maturation of $\mathrm{Ca}^{2+}$-phosphate mineral phases. More recently, it was reported that osteocalcin may act in combination with other hydroxyapatitebinding proteins as a signal for bone remodeling [15]. Osteopontin is thought to promote or regulate the adhesion, attachment, and spreading of osteoclasts to the bone surface during bone resorption $[16,17]$. It is known to be produced by osteoblasts [18-20], as well as osteoclasts $[19,21,22]$. Another protein abundant in bone with potential roles in regulating cellular activities, albeit not in binding the cells, is osteonectin [23]. Studies in vitro have shown roles of osteonectin in modulating cell division and cell migration [23] and perhaps initiating active mineralization in normal skeletal tissue [24]. Bone sialoprotein, similar to osteopontine as a sulfate-protein secreted by osteoblasts, is an early marker of osteoblasts differentiation that plays significant roles in regulating biomineralization [23]. Type I collagen expression is considered an early differentiation marker of the osteoblast phenotype [25-27]; while the expression of osteocalcin, osteopontin, and osteonectin were late differentiation marker as they associated with mineralization of the bone extracellular matrix [28].

In this study, we investigated the influence of SDCP ions on in vitro osteoblasts behavior. This paper reports the evaluation of the bioactivity and biocompatibility of
SDCP prepared at different concentrations $\left(10^{-2}\right.$ $\left.10^{-14} \mathrm{M}\right)$. The biocompatibility has been evaluated by means of cytotoxicity and cytocompatibility tests. Cell proliferation as well as the expression of some biochemical parameters of osteoblastic phenotype (alkaline phosphatase (AP) activity, type I collagen, osteocalcin, osteonectin, and osteopontin production) have been monitored.

\section{Materials and methods}

\subsection{Preparation of sintered $\beta$-dicalcium pyrophosphate solutions}

The powder of sintered $\beta$-dicalcium pyrophosphate (SDCP) was prepared as previously described [2]. In short, the $\beta$-DCP powder ( $\beta$-DCP: $\mathrm{Ca}_{2} \mathrm{P}_{2} \mathrm{O}_{7}$, Sigma, St. Louis, MO, USA) mixed with $5 \mathrm{wt} \% \mathrm{Na}_{4} \mathrm{P}_{2} \mathrm{O}_{7} \cdot 10 \mathrm{H}_{2} \mathrm{O}$ in water and dried at $70^{\circ} \mathrm{C}$ for 3 days. The well-mixed and dried cake was grounded and sieved to obtain 40-60 mesh particles. The sieved particles were placed in a platinum crucible and heated up to $930^{\circ} \mathrm{C}$ at a heating rate of $3^{\circ} \mathrm{C} / \mathrm{min}$ in a conventional $\mathrm{Ni}-\mathrm{Cr}$ coiled furnace and then maintained in air for $1 \mathrm{~h}$ after the sintering temperature of $930^{\circ} \mathrm{C}$ was reached. The obtained SDCP was dissolved by $12 \mathrm{~N}$ hydrogen chloride and then diluted into different concentration of solutions by culture medium used in the bone cell culture. In the first part of this study, the effects of various concentration of SDCP ions on bone cell activities were evaluated by using MTT assay as described below. The highest concentration of SDCP used in this study was $1.0 \times 10^{-2} \mathrm{M}$, because when SDCP ions were higher than $1.0 \times 10^{-2} \mathrm{M}$, the buffering capacity of medium was exceeded and the calcium phosphate precipitations appeared. Thirteen different concentrations $\left(1.0 \times 10^{-2}\right.$ $1.0 \times 10^{-14} \mathrm{M}$ ) were tested for $1,3,7$ and 14 days period. While in the control cultures, an equivalent and molarity of $\mathrm{HCl}$ was added.

\subsection{Osteoblast cell culture}

Sequential digestion of newborn Wistar-rat calvaria was performed by using a modification of the methods described by Wong and Cohn [29]. Briefly, after pretreatment of the dissected calvaria with $4 \mathrm{mM} \mathrm{Na}{ }_{2}$ EDTA in a pre-warmed $\left(37^{\circ} \mathrm{C}\right)$ solution containing $137 \mathrm{~mm} \mathrm{NaCl}, 2.7 \mathrm{~mm} \mathrm{KCl}, 3 \mathrm{~mm} \mathrm{NaH} \mathrm{PO}_{4}, \mathrm{pH} 7.2$ (solution $\mathrm{A}$ ), for $10 \mathrm{~min}$ three times, the fragments were sequential digested with collagenase $(180 \mathrm{U} / \mathrm{ml}$, Sigma, St. Louis, MO, USA) in solution A with EDTA. The sequential digestion consisted of four times' treatments for $5 \mathrm{~min}$ followed by two times' treatments for $10 \mathrm{~min}$. The cells released after each treatment were immediately harvested by centrifugation and resuspended in culture 
medium. Unambiguous identification of cell populations as osteoblasts is complex since none of the parameters used for defining osteoblasts-like cells are unique to this cell types [30]. The presence of AP, an early marker of osteoblasts [31], is used to assess the osteoblastic character of the isolated cells [29,32-34].

\subsection{Colorimetric MTT (Tetrazolium) assay for cell viability [35]}

The mitochondria activity of the bone cells after exposure to various concentrations of SDCP was determined by colorimetric assay which detects the conversion of 3-(4,5-dimethylthiazolyl-2)-2,5-diphenyltetrazolium bromide (MTT, Sigma catalog no. M2128, Sigma Co., St. Louis, MO, USA) to formazan. For the assay, $2.5 \times 10^{4}$ cells/well were incubated $\left(5 \% \mathrm{CO}_{2}, 37^{\circ} \mathrm{C}\right)$ in the presence of various concentration of SDCP ions. After various time intervals the supernatant was removed, $100 \mu \mathrm{l} /$ well of MTT solution $(1 \mathrm{mg} / \mathrm{ml}$ in test medium) was added and the wells were incubated at $37^{\circ} \mathrm{C}$ for $4 \mathrm{~h}$ to allow the formation of formazan crystal. Again the supernatant was removed and acid-isopropanol (100 $\mu \mathrm{l}$ of $0.04 \mathrm{~N} \mathrm{HCl}$ in isopropanol) was added to all wells and mixed thoroughly to dissolve the dark blue crystals. After a few minutes at room temperature to ensure that all crystals were dissolved, the plates were read on Micro Elisa reader (Emax Science Corp., Sunnyvale, CA, USA), using a test wavelength of $570 \mathrm{~nm}$ against a reference wavelength of $690 \mathrm{~nm}$. Plates were normally read within $1 \mathrm{~h}$ after adding the isopropanol.

\subsection{Osteoblast differentiation}

Osteoblasts cultured in the media in the presence of dexamethasone have been shown to be capable of synthesizing and mineralizing an extracellular matrix and to form AP in vitro [36]. To subculture, the cells were washed twice with sterile PBS followed by treatment with $1: 1$ mixture of $0.03 \%$ collagenase (25 U/ml in DMEM only; type VII, Sigma, St. Louis, MO, USA) and $0.05 \%$ trypsin (Sigma, St. Louis, MO, USA) for $20 \mathrm{~min}$ at $37^{\circ} \mathrm{C}$ in $5 \% \mathrm{CO}_{2}$. The resulting cell suspension was then passed and centrifuged at $1500 \mathrm{rpm}$ for $5 \mathrm{~min}$ to pellet the cells. The supernatant was removed and the pellet resuspended in $\alpha$-minimal essential media ( $\alpha$-MEM; Sigma, St. Louis, MO, USA). A concentration of $1 \times 10^{6}$ cells $/ 100 \mu 1$ was added to $35 \mathrm{~mm}$ wells of a 6 -well plate. The osteoblasts were incubated at $37^{\circ} \mathrm{C}$ in $5 \% \mathrm{CO}_{2}$ for $24 \mathrm{~h}$. After $24 \mathrm{~h}$, the media were changed and the cells were incubated in $\alpha$ MEM supplemented with $10 \%$ fetal calf serum (FCS; Gibco BRL, Rockville, MD, USA), antibiotics (gentamicin $50 \mu \mathrm{g} / \mathrm{ml}$, penicillin $\mathrm{G} 100 \mu \mathrm{g} / \mathrm{ml}$ [Gibco BRL, Rockville, MD, USA]), L-ascorbic acid ( $50 \mu \mathrm{g} / \mathrm{ml}$ Gibco BRL, Rockville, MD, USA), supplemented with $5 \mathrm{~mm}$ $\beta$-glycerophosphate (Sigma, St. Louis, MO, USA) and $10^{-8} \mathrm{M}$ dexamethasone (Sigma, St. Louis, MO, USA). The day of subculture was day zero. From day one of culture, $10^{-8}$ м SDCP solution was added. The medium was changed every 3-4 days; AP staining, von Kossa stain for mineralized nodules and bone markers messenger ribonucleic acid (mRNA) isolation and identification were performed at $3 \mathrm{~h}$, day $1,3,7$ and 14 .

\subsection{Alkaline phosphatase activity determination}

After fixing the cells, the dishes were incubated for $30 \mathrm{~min}$ in TRIS Buffer $(0.2 \mathrm{M}, \mathrm{pH} 8.3)$ with AS-MX phosphate (Sigma, St. Louis, MO, USA) as a substrate and Fast Blue (Sigma, St. Louis, MO, USA) as a stain [37]. The AP positive cells stained blue/purple. For each experiment, a minimum of three dishes was counted and the experiments were repeated three times.

\subsection{The von-Kossa staining on mineralized nodules formation}

Since the calcium usually co-precipitate with the phosphate ion in the in vitro culture condition, mineralization of the nodules in the cultures was assessed using von-Kossa stain. The matrix was washed with PBS, and cultures were treated with $5 \%$ silver nitrate solution $100 \mu \mathrm{l} /$ well in the dark at $37^{\circ} \mathrm{C}$ for $30 \mathrm{~min}$. The excess silver nitrate solution was then completely washed away using double-distilled $\mathrm{H}_{2} \mathrm{O}$ and the culture plate was exposed to sodium carbonate/ formaldehyde solution for few minutes to develop color. Mineralized and unmineralized nodules could be distinguished separately: mineralized nodules by their vonKossa-positive staining (dark brown center and light brown peripheral area), and unmineralized nodules by their surface layer of cuboidal cells, light brown staining, and three-dimensional structure. To evaluate bone nodule area precisely, the von-Kossa-stained areas were viewed by light microscopy. For each experiment, a minimum of three dishes was counted and the experiments were repeated three times.

\subsection{Messenger ribonucleic acid ( $m R N A)$ isolation and reverse transcriptase-polymerase chain reaction $(R T-P C R)$}

After a predeterrmined time, the RNA was isolated from osteoblast cells by an acid guanidine method using RTIzol Reagent (Gibco BRL, Rockville, MD, USA) and reverse transcribed to cDNA. For the quantitification of mRNA, the method developed by Nakajima et al. was used [38]. Briefly, 10-fold titrated cDNA ( $1 \mu \mathrm{g}$ RNA-1 pg RNA) was amplified by polymerase chain reaction (PCR). The amplification procedure consisted of 35 cycles $\left(95^{\circ} \mathrm{C}\right.$ for $1 \mathrm{~min}, 58^{\circ} \mathrm{C}$ for $1 \mathrm{~min}$, 
$72^{\circ} \mathrm{C}$ for $10 \mathrm{~min}$ ) with the oligonucleotide primer sets shown in Table 1 . The cDNA amplified by PCR was fractionated by electrophoresis in agarose gel. Relative expression were evaluated by detection of specific band (39, Collagen type I: 1208 bp; 40, Osteocalcin: 462 bp;

Table 1

Oligonucleotide of $5^{\prime}$ and $3^{\prime}$ primers of targets

\begin{tabular}{|c|c|}
\hline Collagen type I & 1208 bp [39] \\
\hline $5^{\prime}$ Primer & $5^{\prime}$-ATGGT GCTCC TGGTG CCA- $3^{\prime}$ \\
\hline $3^{\prime}$ Primer & $5^{\prime}$-TGTAT TCGAT GACTG TCTTG-3' \\
\hline Osteocalcin & 462 bp [40] \\
\hline $5^{\prime}$ Primer & $5^{\prime}$-ATGAG GACCC TCTCT CTGCT CACT-3' \\
\hline $3^{\prime}$ Primer & $5^{\prime}$-ACCGT TCCTC ATCTG GACTT TA-3' \\
\hline Osteonectin & 890 bp [41] \\
\hline $5^{\prime}$ Primer & $\begin{array}{l}5^{\prime} \text {-CTT AGA TCA CCA GAT CCT TGT TGA } \\
\text { TG-3' }\end{array}$ \\
\hline $3^{\prime}$ Primer & $\begin{array}{l}5^{\prime} \text {-CCC AGC ATC ATG AGG GCC TGG ATC } \\
\text { TT- } 3^{\prime}\end{array}$ \\
\hline Osteopontin & $941 \mathrm{bp}[42]$ \\
\hline $5^{\prime}$ Primer & $\begin{array}{l}\text { 5'-CAA CCA TGA GAC TGG CAG TGG TTT } \\
\text { GC-3' }\end{array}$ \\
\hline $3^{\prime}$ Primer & $\begin{array}{l}5^{\prime} \text {-GCC TCT TCT TTA ATT GAC CTC AGA } \\
\text { AG-3' }\end{array}$ \\
\hline
\end{tabular}

41, Osteonectin: $890 \mathrm{bp}$; 42, Osteopontin: $941 \mathrm{bp}$ ) visualized by ethidium bromide staining.

\subsection{Statistical analysis}

All data are expressed as mean \pm standard deviation and were analyzed by analysis of variance (one-way ANOVA). Statistical significance was determined by Bonferroni's $t$-test . Probability values less than 0.05 were considered significant.

\section{Results}

\subsection{Quantitative analysis of osteoblast cell counts}

MTT [3-(4,5-dimethylthiazolyl-2)-2,5-diphenyltetrazolium bromide] is a pale yellow substrate that produces a dark blue formazan product when incubated with living cells. MTT ring is cleaved in active mitochondria, and the reaction occurs only in living cells [35]. Fig. 1 shows the effect of various concentrations of SDCP ions on osteoblast cells viability measured by MTT assay. When osteoblast cells cultured with $10^{-2} \mathrm{M}$ or $10^{-3} \mathrm{M}$
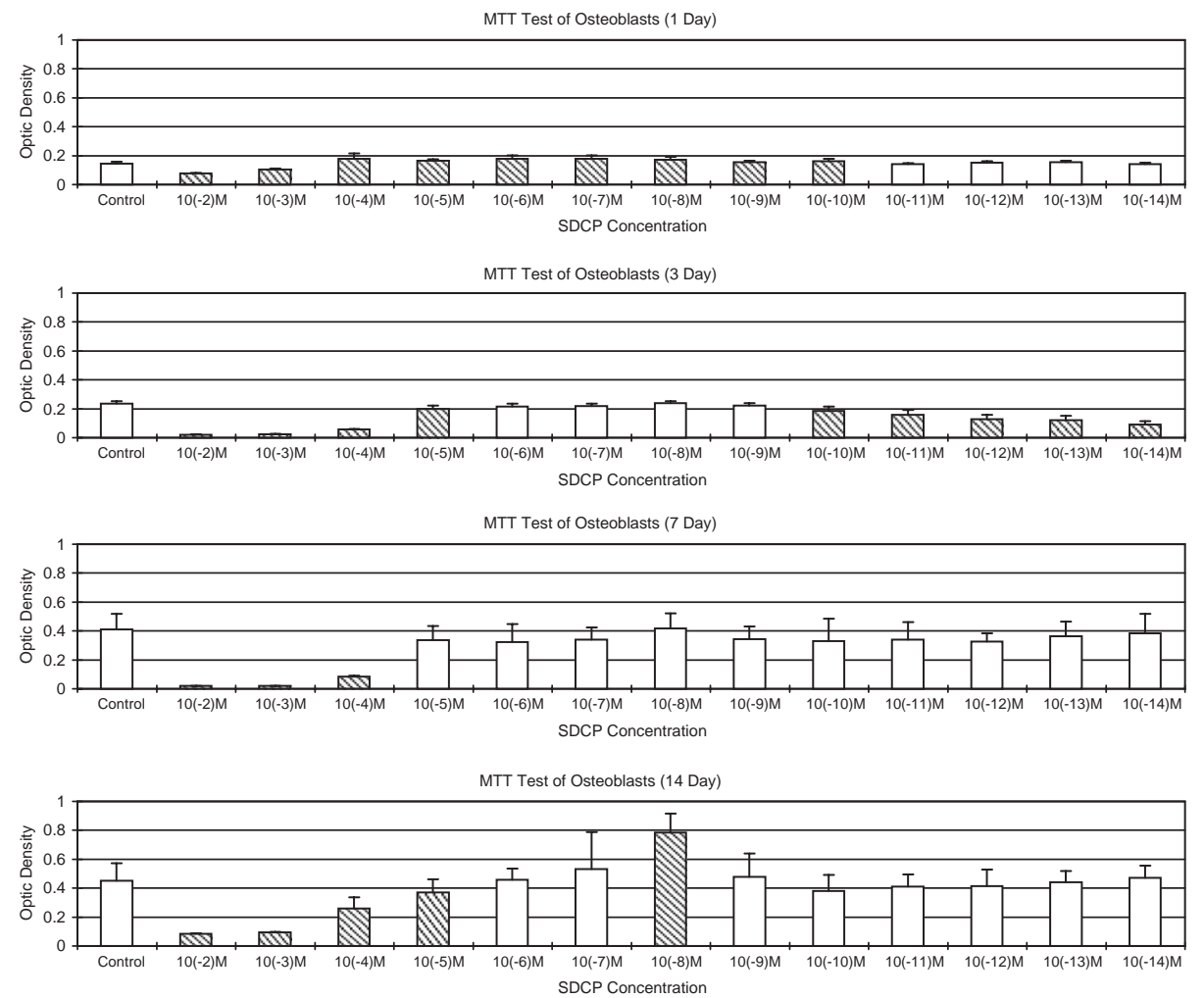

Fig. 1. The effect of various concentrations of SDCP ions on osteoblast cells viability $(N=12)$. When osteoblast cells cultured with $10^{-2} \mathrm{M}$ or $10^{-3} \mathrm{M}$ SDCP for one day, there was significant decrease in the formation of formazan; while in the $10^{-4} \mathrm{M}$ or $10^{-10} \mathrm{M}$ concentration of SDCP, the formation of formazan was significantly increased. At the $10^{-8} \mathrm{M}$ concentration of SDCP, the beneficial effect on the osteoblasts attained peak at the end of 3 days' culture, although it did not attain the significant level. (Shadowed bar mean the difference attained a statistically significant difference, i.e., $P<0.05$.) 


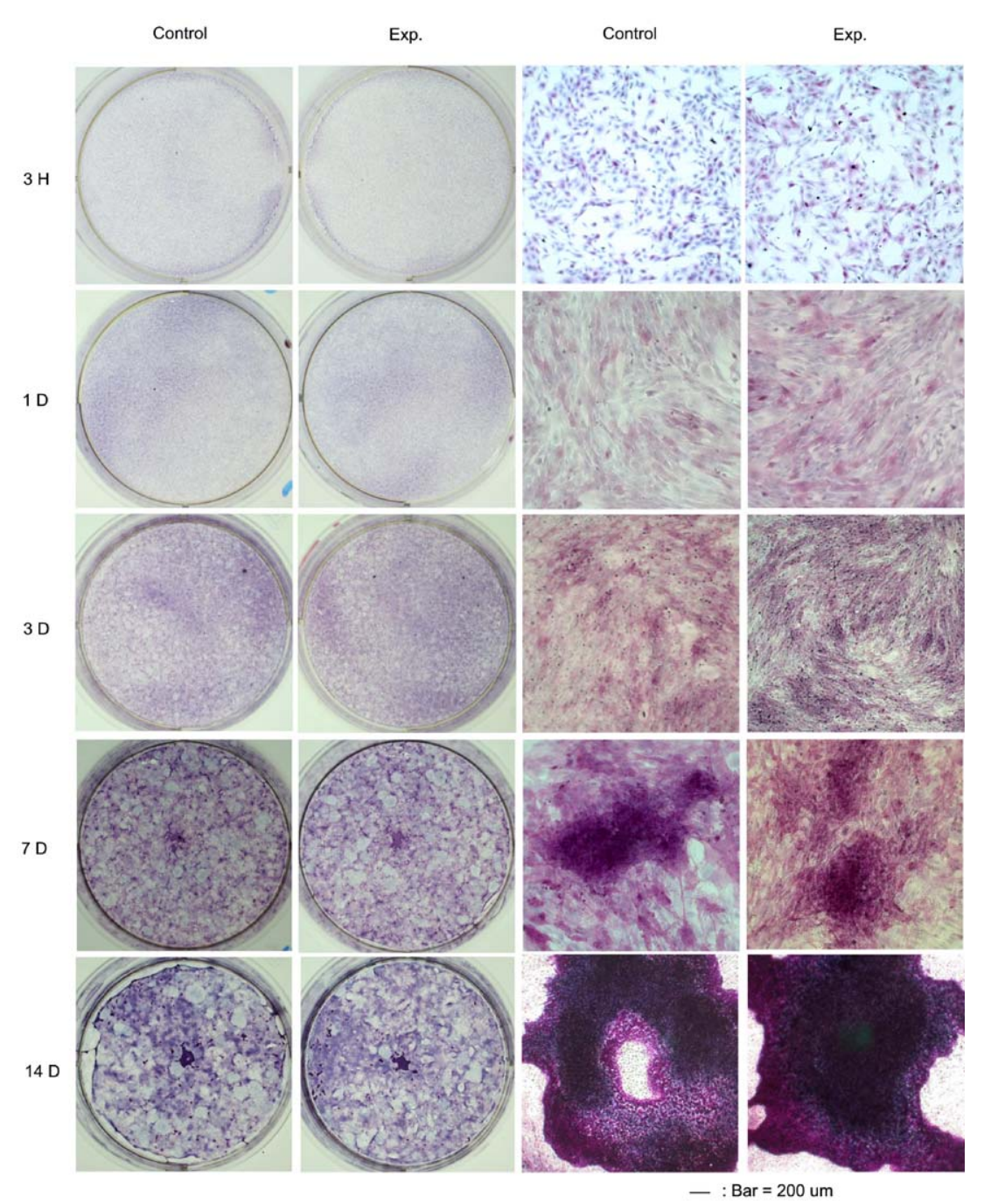

Fig. 2. Photomicrograph of AP staining for the differentiation of osteoblasts in the medium containing $5 \mathrm{~mm} \beta$-glycerophosphate and $10^{-8} \mathrm{M}^{-}$ dexamethasone. At $3 \mathrm{~h}$ after differentiation medium, there was little AP positive staining colony was found in the culture. The AP positive staining colonies first appeared at the 1st day's culture, and then progressively increased as the culture period passed, and attained a significant degree at the 14th day's culture. Similar result was observed in the group cultured with $10^{-8} \mathrm{M}$ concentration of SDCP ions. (Control: control group; Exp. Study group with $10^{-8} \mathrm{M}$ concentration of SDCP ions; bar $=200 \mu \mathrm{m}$.)

SDCP for one day, there was significant decrease in the formation of formazan; while in the $10^{-4} \mathrm{M}$ or $10^{-10} \mathrm{M}$ concentration of SDCP, the formation of formazan was significantly increased in the first day's culture (Fig. 1). At the $10^{-8} \mathrm{M}$ concentration of SDCP, the beneficial effect on the osteoblasts attained to the end of 14 days' culture, although it did not attain the significant level at the 3rd and 7th days' culture (Fig. 1). We selected the $10^{-8} \mathrm{M}$ concentration of SDCP ions for the further biochemical study.

\subsection{Alkaline phosphatase staining and mineralized nodules formation}

When cultured in the medium containing $5 \mathrm{~mm} \beta$ glycerophosphate and $10^{-8} \mathrm{M}$ dexamethasone, the os- teoblasts differentiated as the cultured period increased. At $3 \mathrm{~h}$ after differentiation medium, little AP positive staining colony was found in the culture. The AP positive staining colonies first appeared at the 1st day's culture of control groups, and then progressively increased as the culture period passed, and attained a significant degree at the 14th day's culture (Fig. 2). Similar result was observed in the group cultured with $10^{-8} \mathrm{M}$ concentration of SDCP ions (Fig. 2). The addition of SDCP ions on the osteoblast cultures also did not affect the formation of mineralization nodules, and similar results were observed on the von-Kossa staining (Fig. 3). The qualitative analysis of ALP and mineralization were repeated in triplicate which showed similar result. The formation of AP positive staining colonies and mineralization nodules formation in the 


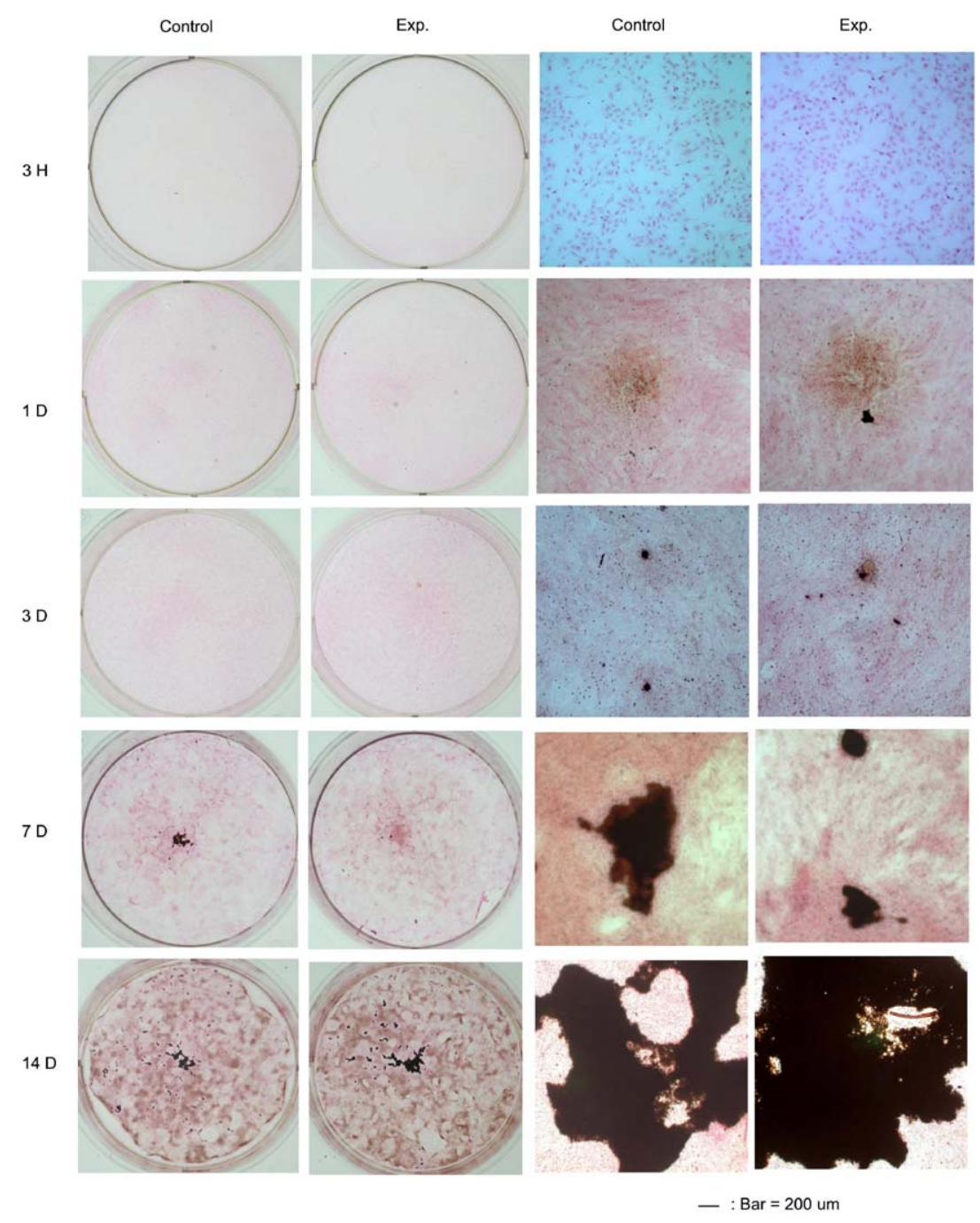

Fig. 3. Photomicrograph of von-Kossa staining for the mineralized nodules formation of the osteoblasts in the medium containing 5 mm $\beta$ glycerophosphate and $10^{-8} \mathrm{M}$ dexamethasone. At $3 \mathrm{~h}$ after differentaitaion medium, there little von-Kossa positive staining colony was found in the culture. The von-Kossa positive staining colonies first appeared at the 1st day's culture, and then progressively increased as the culture period passed, and attained a significant degree at the 14th day's culture. Similar result was observed in the group cultured with $10^{-8} \mathrm{M}$ concentration of SDCP ions. (Control: control group; Exp. Study group with $10^{-8} \mathrm{M}$ concentration of SDCP ions; bar $=200 \mu \mathrm{m}$.)

osteoblast cultures were not significantly affected by SDCP ions.

\subsection{Reverse transcriptase-polymerase chain reaction}

In this model, osteoblasts have been known to express type I collagen, osteonectin and osteopontin mRNA at the $3 \mathrm{~h}$ culture, then attained their maximal expression at the first day's culture. The osteocalcin mRNA expression was quite low in the first 3 days' culture and then appeared at the 7th day's culture. In the presence of on $10^{-8} \mathrm{M}$ SDCP ions, type I collagen, osteonectin and osteopontin mRNA expression were down-regulated at the $3 \mathrm{~h}$ culture and then returned to that of control level at the day 1. The osteocalcin mRNA expression was up-regulated in the first 3 days' culture and returned to that of control level at the day 7 (Fig. 4). When osteoblasts cultured in the presence of $10^{-8} \mathrm{M}$ SDCP ions, the osteocalcin mRNA expression was up-regulated; while the collagen, osteonectin and osteopontin mRNA expression were down-regulated than that of the control.

\section{Discussion}

Continuous advances in the field of implantable calcium phosphate bioceramics have produced impres- 


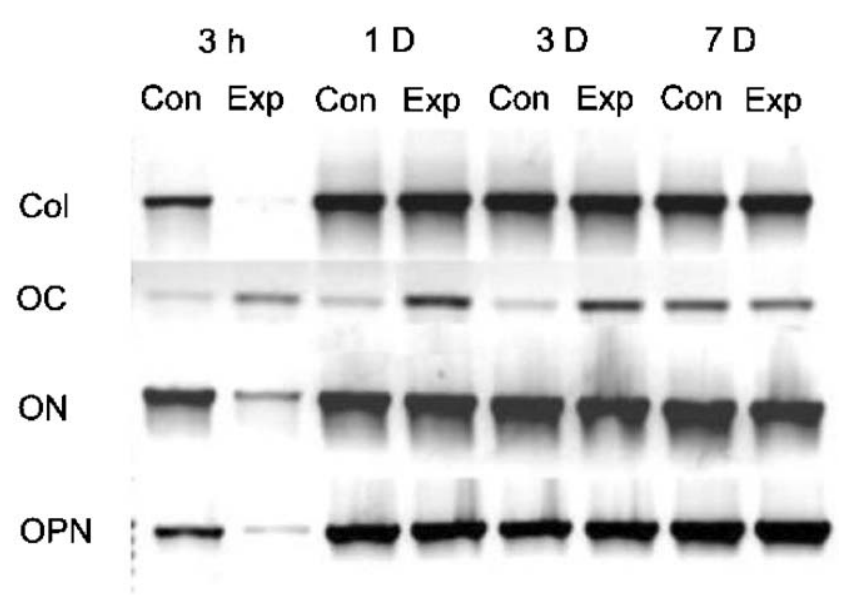

Fig. 4. The effect of various concentrations of SDCP ions on bone markers expression by RT-PCR. In this model, osteoblasts have been known to express collagen type I, osteonectin and osteopontin mRNA at the $3 \mathrm{~h}$ culture, then attained their maximal expression at the first day's culture. The osteocalcin mRNA expression was quite low in the first 3 days' culture and then appeared at the 7th day's culture. In the presence of on $10^{-8} \mathrm{M}$ SDCP ions, collagen type I, osteonectin and osteopontin mRNA expression were down-regulated at the $3 \mathrm{~h}$ culture and then returned to that of control at the day 1 . The osteocalcin mRNA expression was up-regulated in the first 3 days' culture and returned to that of control at the day 7 . When osteoblasts cultured in the presence of $10^{-8} \mathrm{M}$ SDCP ions, the osteocalcin mRNA expression was up-regulated; while the collagen, osteonectin and osteopontin mRNA expression were down-regulated than that of the control. (Con.: control group; Exp. Study group with $10^{-8} \mathrm{M}$ concentration of SDCP ions; Col: Type I collagen; OC: osteocalcin; ON: osteonectin; OPN: osteopontin.)

sive progress with respect to their biocompatibility and have shown an ability to promote tissue formation. Biodegradable biomaterials have found a wide variety of applications in clinical medicine. Certain biodegradable calcium phosphates have been used as bone substitutes to avoid the complications associated with bone grafts, such as the shortage of supply, the immunogenicity, and the transfer of disease with the graft [43-46]. One of the main advantages of biodegradable substances is that it obviates the need for eventual surgical removal. SDCP has been proved to have great potential as an in vivo biodegradable bone substitute $[2,47]$. Recent work in our institute has also demonstrated that the ingestion of SDCP decreased the bony porosity and increased bone mineral contents in the ovariectomized rats [12]. In the in vitro model, SDCP has been proved to be more biocompatible than hydroxyapatite [10]. Later, we demonstrated that SDCP can induce apoptosis of osteoclasts in an ultrastructural model characterized by changes of the nucleus accompanied by degradation of cellular organelles [13]. However, it has not been possible to define the molecular mechanisms that mediated these processes; whether stimulation of bone synthesis by SDCP occurs through direct contact between substrate and cells or through soluble ions released by SDCP during is still unknown. In the previous study, it has been shown that osteoclast differentiation and activation are thought to be mediated through modulation of paracrine factors produced by osteoblastic lineage cells [48]. In this study, we investigated the influence of SDCP ions on in vitro osteoblasts behavior.

From MTT assay of this study, we observed cells proliferation was significantly $(p<0.05)$ increased in the first day's culture when osteoblasts were cultured with $10^{-4}-10^{-10} \mathrm{M}$ concentration of SDCP ions. At the $10^{-8} \mathrm{M}$ concentration of SDCP, the beneficial effect on the osteoblasts attained to the end of 14 days' culture, although it did not attain the significant level at the $3 \mathrm{rd}$ and 7th days' culture (Fig. 1). The concentration of $10^{-8}$ M SDCP ions was selected for the further biochemical study.

The differentiation of osteoblastic cells in culture involves a programmed developmental sequence $[25,26]$. The proliferation of cells in culture usually follows a standard pattern, with an initial lag-phase (period of adaptation during which the cell replaces elements of the cell surface and extracellular matrix lost during trypsinization), followed by the log-phase (phase of exponential increase in cell number, during which osteoblastic cells are relatively undifferentiated), and the plateau phase (in which cell division is balanced by cell loss and bone cell phenotypic markers are expressed). In general, cell cultures are most consistent and uniform in the logphase, and sampling at day 6 gives a high yield and reproducibility of proliferative activity in osteoblast cells $[49,50]$. The increased cell number with $10^{-8} \mathrm{M}$ SDCP ions at day 1 possibly was caused by an increased growth rate during the lag-phase or an extended lagperiod, implying a stimulation effect of SDCP ions on the cells during this phase. The cell number was quite similar between the groups with and without $10^{-8} \mathrm{M}$ SDCP ions at days 3 and 7, implying the stimulation effect of SDCP ions on the cells possibly was not evident during the log-phase. The increased cell number with $10^{-8} \mathrm{M}$ SDCP ions appeared again at day 14 , implying a stimulation effect of SDCP ions on the cells during the plateau phase.

To assess the influence of surface composition on bone cell specific markers, AP staining, von-Kossa staining on mineralized nodules formation, collagen Type I, osteocalcin, and osteonectin production were measured. Osteoblast differentiation is a multistep series of events modulated by an integrated cascade of gene expression that initially supports proliferation and the sequential expression of genes associated with the matrix maturation, and mineralization of the bone extracellular matrix [28]. AP expression is considered an early differentiation marker of the osteoblast phenotype, while the von-Kossa stain of mineralized nodules 
formation represented the end differentiation marker of the osteoblasts. In this study, the differentiation of osteoblasts was induced when $\beta$-glycerophosphate and dexamethasone were added into the culture medium [36,51], the degree of differentiation increased as the cultured period increased (Figs. 2 and 3) and cultures of osteoblasts also had detectable calcium deposition, as seen on von-Kossa staining by days 7-14 after the cells reached confluency [52]. However, the formation of AP positive staining colonies and mineralization nodules formation in the osteoblast cultures were not significantly affected by adding of $10^{-8} \mathrm{M}$ SDCP ions. Although the von-Kossa stain is a measure of phosphate ion precipitation, the possibility of ectopic mineralization due to the cultures been grown in the presence of the exogenous calcium phosphate and $\beta$-glycerophosphate can be excluded since the similar results were observed in the control samples.

Recent research shows that there is genetic control of the cellular response of osteoblasts to bioactive glasses. Several families of genes are up-regulated within $48 \mathrm{~h}$ of the exposure of primary human osteoblasts to the ionic dissolution products of bioactive glasses [53]. The activated genes express numerous proteins that influence all aspects of differentiation and proliferation of osteoblasts. RT-PCR analysis was used in this study to evaluate the cell-biomaterials interactions at the genetic level. For the evaluation of RNA expression, northern blotting analysis is used as usual, but this requires more than $1 \mu \mathrm{g}$ mRNA for one sample; i.e., over $10^{7}$ cells are needed to obtain $1 \mu \mathrm{g}$ mRNA, so it is difficult to use northern blotting for studying cell-biomaterials interactions [54]. In fact, RT-PCR analysis seemed to fit our purpose, as it needs only a small amount (pg) of mRNA for detection.

When osteoblasts cultured in the presence of $10^{-8} \mathrm{M}$ SDCP ions, the osteocalcin mRNA expression was upregulated during the first 3 days' culture; while the collagen, osteonectin and osteopontin mRNA expression were down-regulated in the first $3 \mathrm{~h}$ culture (Fig. 4). In the current study, the amount of osteocalcin mRNA expression attained its highest amount at the day 7 . The osteocalcin, osteonectin and osteopontin mRNA expression reached their maximal earlier than the mineralization process, indicating an increased proportion of non-collagenous proteins, including osteocalcin, osteonectin and osteopontin being bound to the collagen matrix or hydroxyapatite mineral $[15,55]$.

Despite encouraging preliminary in vivo reports about improvement with the use of SDCP in treatment of osteoporosis after ovariectomy, basic-science and controlled study reported to date still have not established yet. In this study, we demonstrated that elevated concentration of calcium and pyrophosphate ions can activate genes of the bone cells. This study will contribute to a better understanding of cell/biomaterial interactions and mechanisms that SDCP ions affect the bone cells. Although our study had limitations and our findings are preliminary, continued and advanced study on the alterations in gene expression of bone cells by SDCP will provide a basis for understanding the observed the bone cells responses to various biomedical and pharmacological interventions.

\section{Acknowledgements}

The authors sincerely thank the National Science Council, R.O.C. for their financial support of this research.

\section{References}

[1] Hench LL, Polak JM. Third-generation biomedical materials. Science 2002;295:1014-7.

[2] Lin FH, Lin CC, Lu CM, Liu HC, Sun JS, Wang CY. Mechanical properties and histological evaluation of sintered beta- $\mathrm{Ca}_{2} \mathrm{P}_{2} \mathrm{O}_{7}$ with $\mathrm{Na}_{4} \mathrm{P}_{2} \mathrm{O}_{7} \cdot 10 \mathrm{H}_{2} \mathrm{O}$ addition. Biomaterials 1995;16:793-802.

[3] Gregoire M, Orly I, Menanteau J. The influence of calcium phosphate biomaterials on human bone cell activities. An in vitro approach. J Biomed Mater Res 1990;24:165-77.

[4] Davies JE. In vitro modeling of the bone/implant interface. Anat Rec 1996;245:426-45.

[5] Kawai N, Niwa S, Sato M, Sato Y, Suwa Y, Ichihara I. Bone formation by cells from femurs cultured among three-dimensionally arranged hydroxyapatite granules. J Biomed Mater Res 1997; 37:1-8.

[6] Acil Y, Terheyden H, Dunsche A, Fleiner B, Jepsen S. Threedimensional cultivation of human osteoblast-like cells on highly porous natural bone mineral. J Biomed Mater Res 2000;51: 703-10.

[7] Zambonin G, Losito I, Triffitt JT, Zambonin CG. Detection of collagen synthesis by human osteoblasts on a tricalcium phosphate hydroxyapatite: an X-ray photoelectron spectroscopy investigation. J Biomed Mater Res 2000;49:120-6.

[8] Beckham CA, Greenlee Jr TK, Crebo AR. Bone formation at a ceramic implant interface. Calcif Tissue Res 1971;8:165-71.

[9] Yamada S, Heymann D, Bouler JM, Daculsi G. Osteoclastic resorption of biphasic calcium phosphate ceramic in vitro. J Biomed Mater Res 1997;37:346-52.

[10] Sun JS, Tsuang YH, Liao CJ, Liu HC, Hang YS, Lin FH. The effects of calcium phosphates particles on the growth of osteoblast. J Biomed Mater Res 1997;37:324-34.

[11] Harris ST, Gertz BJ, Genant HK, Eyre DR, Survill TT, Ventura JM, DeBrock J, Ricerca E, Chesnut III CH. The effect of short term treatment with alendronate on vertebral density and biochemical markers of bone remodeling in early postmenopausal women. J Clin Endocrinol Metab 1993;76:1399-406.

[12] Sun JS, Huang YC, Tsuang YH, Chen LT, Lin FH. Sintered dicalcium pyrophosphate increases bone mass in the ovariectomized rats. J Biomed Mater Res 2002;59:246-53.

[13] Sun JS, Huang YC, Lin FH, Chen LT. The effect of sintered dicalcium pyrophosphate on osteoclast metabolism: an ultrastructural study. J Biomed Mater Res 2003;64A:616-21.

[14] Von der Mark K. Structure, biosynthesis, and gene regulation of collagens in cartilage and bone. In: Seibel MJ, Robins SP, Bilezikian JP, editors. Dynamics of bone and cartilage metabolism. San Diego: Academic Press; 1999. p. 3-29. 
[15] Gunberg CM, Nishimoto SK. Vitamin K-Dependent proteins of bone and cartilage. In: Seibel MJ, Robins SP, Bilezikian JP, editors. Dynamics of bone and cartilage metabolism. San Diego: Academic Press; 1999. p. 45-53.

[16] Reinholt FP, Hultenby K, Oldberg A, Heinegard D. Osteopontin - a possible anchor of osteoclasts to bone. Proc Natl Acad Sci USA 1990;87:4473-5.

[17] Ikeda T, Nomura S, Yamaguchi A, Suda T, Yoshiki S. In situ hybridization of bone matrix proteins in undecalcified adult rat bone sections. J Histochem Cytochem 1992;40: 1079-88.

[18] Weinreb M, Shinar D, Rodan GA. Different pattern of alkaline phosphatase, osteopontin, and osteocalcin expression in developing rat bone visualized by in situ hybridization. $\mathbf{J}$ Bone Mineral Res 1990;5:831-42.

[19] Merry K, Dodds R, Littlewood A, Gowen M. Expression of osteopontin mRNA by osteoclasts and osteoblasts in modelling adult human bone. J Cell Sci 1993;104:1013-20.

[20] Hirakawa K, Hirota S, Ikeda T, Yamaguchi A, Takemura T, Nagoshi J, Yoshiki S, Suda T, Kitamura Y, Nomura S. Localization of the mRNA for bone matrix proteins during fracture healing as determined by in situ hybridization. J Bone Mineral Res 1994;9:1551-7.

[21] Tezuka K, Sato T, Kamioka H, Nijweide PJ, Tanaka K, Matsuo T, Ohta M, Kurihara N, Hakeda Y, Kumegawa M. Identification of osteopontin in isolated rabbit osteoclasts. Biochem Biophys Res Commun 1992;186:911-7.

[22] Dodds RA, Ali N, Pead MJ, Lanyon LE. Early loadingrelated changes in the activity of glucose 6-phosphate dehydrogenase and alkaline phosphatase in osteocytes and periosteal osteoblasts in rat fibulae in vivo. J Bone Mineral Res 1993;8: 261-7.

[23] Lane TF, Sage EH. The biology of SPARC, a protein that modulates cell-matrix interactions. FASEB J 1994;8:163-73.

[24] Termine JD, Kleinman HK, Whitson SW, Conn KM, McGarvey ML, Martin GR. Osteonectin, a bone-specific protein linking mineral to collagen. Cell 1981;26:99-105.

[25] Stein GS, Lian JB. Molecular mechanisms mediating proliferation/differentiation interrelationships during progressive development of the osteoblast phenotype. Endocr Rev 1993;1: 424-42.

[26] Stein GS, Lian JB, Owen TA. Relationship of cell growth to the regulation of tissue-specific gene expression during osteoblast differentiation. FASEB J 1990;4:3111-23.

[27] Lynch MP, Stein JL, Stein GS, et al. The influence of type I collagen on the development and maintenance of the osteoblast phenotype in primary and passaged rat calvarial osteoblasts: modification of expression of genes supporting cell growth, adhesion, and extracellular matrix mineralization. Exp Cell Res 1995;216:35-45.

[28] Stein GS, Lian JB, Stein JL, Van Wijnen AJ, Montecino M. Transcriptional control of osteoblast growth and differentiation. Physiol Rev 1996;76:593-629.

[29] Wong GL, Cohn DV. Target cells in bone for parathormone and calcitonin are different: enrichment for each cell type by sequential digestion of mouse calvaria and selective adhesion to polymeric surfaces. Proc Natl Acad Sci USA 1975;72:3167-71.

[30] Bellows CG, Aubin JE, Heersche JNM, Antosz ME. Mineralized bone nodules formed in vitro from enzymatically released rat calvaria cell populations. Calcif Tissue Int 1986;38:143-54.

[31] Caplan AI, Pechak DG. The cellular and molecular embryology of bone formation. In: Peck C, editor. Bone and mineral research, Vol. 5. Amsterdam: Elsevier; 1987. p. 117-83.

[32] Hall AK, Dickson IR. The effects of parathyroid hormone on osteoblast-like cell from embryonic chick calvaria. Acta Endocrinol 1985;108:217-23.
[33] Begley CT, Doherty MJ, Kankey DP, Wilson DJ. The culture of human osteoblasts growth upon bone graft substitutes. Bone 1993;14:661-7.

[34] Doherty MJ, Schlag G, Schwarz N, Mollan RAB, Nolan PC, Wilson DJ. Biocompatibility of xenogeneic bone, commercially available coral, a bioceramic and tissue sealant for human osteoblasts. Biomaterials 1994;15:601-8

[35] Mosmann T. Rapid colorimetric assay for cellular growth and survival: application to proliferation and cytotoxicity assay. J Immunol Methods 1983;65:55-63.

[36] Gundle R, Beresford JN. The isolation and culture of cells from explants of human trabecular bone. Calcif Tissue Int 1995;56: S8-10.

[37] Burnstone M. Histochemical observation on enzymatic processes in bone and teeth. Ann NY Acad Sci 1960;85:431-44.

[38] Nakajima T, Aono H, Hasunuma T, Yamamoto K, Maruyama I, Nosaka T, Hatanaka M, Nishioka K. Overgrowth of human synovial cells driven by the human $\mathrm{T}$ cell leukemia virus type I tax gene. J Clin Invest 1993;92:186-93.

[39] Genovese C, Rowe D, Kream B. Construction of DNA sequences complementary to rat alpha-1 and alpha-2 collagen mRNA and their use in studying the regulation of type I collagen synthesis by 1,25-dihydroxyvitamin D. Biochemistry 1984;23: 6210-6.

[40] Lian J, Stewart C, Puchacz E, Mackowiak S, Shalhoub V, Collart D, Zambetti G, Stein G. Structure of the rat osteocalcin gene and regulation of vitamin D-dependent expression. Proc Natl Acad Sci USA 1989;86:1143-7.

[41] Lee MJ, Saijoh K, Nestler EJ, Duman RS, Sumino K. Regional differences in expression of osteonectin mRNA after administration of calcium to rats. Full staff reviewed, 1995, unpublished.

[42] Oldberg A, Franzen A, Heinegard D. Cloning and sequence analysis of rat bone sialoprotein (osteopontin) cDNA reveals an Arg-Gly Asp cell binding sequence. Proc Natl Acad USA 1986;83:8819-23.

[43] Bos GD, Goldberg VM, Zika JM, Heiple KG, Powell AE. Immune response of rats to frozen bone allografts. J Bone Jt Surg 1983;65A:239-46.

[44] Hollinger JO, Battisone GC. Biodegradable bone repair materials: synthetic polymers and ceramics. Clin Orthop 1986;207: 290-305.

[45] Mankin HJ, Gebhardt MC, Tomford WW. The use of frozen cadaveric allografts in the management of patients with bone tumors of the extremities. Orthop Clin N Am 1987;18:275-89.

[46] Urist MR, Dawson E. Intertransverse process fusion with aid of chemosterilized autolyzed antigen-extracted allogeneic (AAA) bone. Clin Orthop 1981;154:97.

[47] Lin CC, Liao CJ, Sun JS, Liu HC, Lin FH. Prevascularized bone graft cultured in sintered porous beta- $\mathrm{Ca}_{2} \mathrm{P}_{2} \mathrm{O}_{7}$ with $5 \mathrm{wt} \%$ $\mathrm{Na}_{4} \mathrm{P}_{2} \mathrm{O}_{7} \cdot 10 \mathrm{H}_{2} \mathrm{O}$ addition ceramic chamber. Biomaterials 1996; 17:1133-40.

[48] O'Brien EA, Williams JH, Marshall MJ. Osteoprotegerin is produced when prostaglandin synthesis is inhibited causing osteoclasts to detach from the surface of mouse parietal bone and attach to the endocranial membrane. Bone 2001;28: 208-14.

[49] Freshney RI. Culture of Animal Cells. Edition 4. New York: Wiley-Liss; 2000. p. 309-28.

[50] Goldring SR, Wang JT. Molecular biological approaches to investigate cell/biomaterial interactions. In: Davies JE, editor. The bone-biomaterial interface. Toronto: University of Toronto Press; 1991. p. 241-9.

[51] Coelho MJ, Fernandes MH. Human bone cell cultures in biocompatibility testing. Part II: effect of ascorbic acid, betaglycerophosphate and dexamethasone on osteoblastic differentiation. Biomaterials 2000;21:1095-102. 
[52] Harris SA, Enger RJ, Riggs BL, Spelsberg TC. Development and characterization of a conditionally immortalized human fetal osteoblastic cell line. J Bone Miner Res 1995;10:178-86.

[53] Ioannis D, Xynos ID, Edgar AJ, Buttery LDK, Hench LL, Polak JM. Gene-expression profiling of human osteoblasts following treatment with the ionic products of Bioglass ${ }^{\circledR} 45 \mathrm{~S} 5$ dissolution. J Biomed Mater Res 2001;55:151-7.
[54] Kishida A, Kato S, Ohmura K, Sugimura K, Akashi M. Evaluation of biological response to polymeric biomaterials by RT-PCR analysis. Biomaterials 1996;17:1301-5.

[55] Raif EM, Harmand MF. Molecular interface characterization in human bone matrix: I. biochemical and IR spectroscopic studies. Biomaterials 1993;14:978-84. 